\title{
Steady-State Analysis and Comparison of Control Strategies for PMSM
}

\author{
Jyoti Agrawal $^{1}$ and Sanjay Bodkhe ${ }^{2}$ \\ ${ }^{1}$ Department of Electrical Engineering, G. H. Raisoni College of Engineering, CRPF Gate No. 3, Hingna Road, \\ Digdoh Hills, Nagpur, Maharashtra 440016, India \\ ${ }^{2}$ Department of Electrical Engineering, Shri Ramdeobaba College of Engineering \& Management, \\ 601/K Choti Dhantoli, Nagpur, Maharashtra 440012, India
}

Correspondence should be addressed to Jyoti Agrawal; jyotigovindagrawal@gmail.com

Received 20 September 2015; Accepted 17 November 2015

Academic Editor: ShengKai Yu

Copyright (C) 2015 J. Agrawal and S. Bodkhe. This is an open access article distributed under the Creative Commons Attribution License, which permits unrestricted use, distribution, and reproduction in any medium, provided the original work is properly cited.

\begin{abstract}
Permanent Magnet Synchronous Motor (PMSM) has been considered as the best choice for numerous applications. To make PMSM a high performance drive, effective control system is required. Vector control is accepted widely due to its decoupling effect but it is not the only performance requirement. Additional control methods such as constant torque angle control (CTAC), optimum torque per ampere control (OTPAC), unity power factor control (UPFC), constant mutual flux linkages control (CMFLC), and angle control of air gap flux and current phasor (ACAGF) can also be implemented. This paper therefore presents some important control strategies for PMSM along with merits and limitations which provide a wide variety of control choices in many applications. The performance characteristics for each strategy under steady state are modelled and simulated in MATLAB environment. Based on the simulation results, a conclusion is drawn that OTPAC is superior in normalized torque per unit normalized stator current $\left(T_{e n} / i_{s n}\right)$ ratio whereas UPFC yields very low $T_{e n} / i_{s n}$ ratio. In addition, performances of these control strategies are compared, which is a key to select optimum strategy depending on requirements. Based on the comparative study, it can be concluded that CMFLC is superior to CTAC, ACAGF, OTPAC, and UPFC. Hence, it can be a good control strategy to consider.
\end{abstract}

\section{Introduction}

Recently, PMSM drive has emerged as a top competitor amongst AC drives for industrial servo drives, hybrid electric vehicles, and other applications due to features like high speed, low power waste, large starting torque, high power factor, and high efficiency [1-4]. Also control of PMSM is comparatively simpler than that of induction motor and high performance of PMSM can be achieved by means of vector control as it provides decoupled control of torque and flux $[5,6]$. But decoupled control of torque and flux is not only the performance requirement for PMSM drive [7]. Therefore, in this paper, different control strategies such as constant torque angle control, optimum torque per ampere control, unity power factor control, constant mutual air gap flux linkages control, and angle control of air gap flux and current phasor are considered in detail for the variable speed motor drive. For the speeds lower than base speed, the control strategies for PMSM are constant torque angle control, optimum torque per ampere control, unity power factor control, constant mutual air gap flux linkages control, and maximum efficiency control, while, for the speeds higher than base speed, control strategies are six-step voltage and constant back emf [8]. The comprehensive analysis of control strategies for the speeds lower than base speeds is made and compared in this paper. With the help of phasor diagrams, this paper analyses the characteristics of both surface and interior mounted permanent magnet motors. Each of these control strategies has its own merits and limitations. For example, the constant torque angle control forces the electromagnetic torque to be proportional to the stator current magnitude but results in low power factor, optimum torque per ampere current control strategy provides maximum electromagnetic torque for a given stator current, a unity 
power factor control strategy optimizes the volt ampere (VA) requirement of the system, and a constant mutual air gap flux linkages control limits the flux linkage of the air gap equal to rotor permanent magnet flux linkage which helps to avoid the saturation of core. Similarly, a maximum efficiency control reduces the net loss in the motor and is appropriate for applications where saving the energy is important [8]. A detail analysis and comparison of these control strategies have been made so as to choose the control strategy that optimizes the operation of a particular speed control system.

This paper is organized in the following manner: Section 1 begins by providing a brief introduction about PMSMs and a study of different existing control strategies. In Section 2, the dynamic model and decoupled control of PMSM are explained shortly. Section 3 presents the detailed derivation and implementation of five control strategies for PMSM drive. In Section 4, simulation results are presented to verify the unique feature and capability of the control strategies introduced in the paper emphasizing their merits. The comparison of control strategies based on current, voltage, VA rating, and power factor requirement as a function of torque is described in Section 5. Finally, the conclusions are summarized in Section 6

\section{Dynamic Model and Decoupled Control of PMSM}

In general, the dynamic equations of $d$ - and $q$-axes stator voltages of a PMSM in rotor reference frame are [9]

$$
\begin{aligned}
& v_{d s}^{r}=\left(R_{s}+L_{d} p\right) i_{d s}^{r}-\omega_{r} L_{q} i_{q s}^{r}, \\
& v_{q s}^{r}=\left(R_{s}+L_{q} p\right) i_{q s}^{r}+\omega_{r}\left(L_{d} i_{d s}^{r}+\lambda_{\mathrm{af}}\right) .
\end{aligned}
$$

The stator voltage phasor magnitude is given by

$$
V_{s}=\sqrt{\left(v_{d s}^{r}\right)^{2}+\left(v_{q s}^{r}\right)^{2}}
$$

The phase voltages in $a-b-c$ frame are obtained from the above $d-q$ voltages by using the inverse Park transformation as defined in the following:

$$
\left[\begin{array}{c}
v_{a s} \\
v_{b s} \\
v_{c s}
\end{array}\right]=\left[\begin{array}{ccc}
\cos \theta_{r} & \sin \theta_{r} & 1 \\
\cos \left(\theta_{r}-\frac{2 \pi}{3}\right) & \sin \left(\theta_{r}-\frac{2 \pi}{3}\right) & 1 \\
\cos \left(\theta_{r}+\frac{2 \pi}{3}\right) & \sin \left(\theta_{r}+\frac{2 \pi}{3}\right) & 1
\end{array}\right]\left[\begin{array}{c}
v_{q s}^{r} \\
v_{d s}^{r} \\
v_{0}
\end{array}\right]
$$

Similarly, the relationship between $d-q-o$ and $a-b-c$ currents is obtained through the Park transformation as defined in the following:

$$
\begin{aligned}
& {\left[\begin{array}{c}
i_{q s}^{r} \\
i_{d s}^{r} \\
i_{0}
\end{array}\right]} \\
& =\left[\begin{array}{ccc}
\cos \theta_{r} & \cos \left(\theta_{r}-\frac{2 \pi}{3}\right) & \cos \left(\theta_{r}+\frac{2 \pi}{3}\right) \\
\sin \theta_{r} & \sin \left(\theta_{r}-\frac{2 \pi}{3}\right) & \sin \left(\theta_{r}+\frac{2 \pi}{3}\right) \\
\frac{1}{2} & \frac{1}{2} & \frac{1}{2}
\end{array}\right]\left[\begin{array}{l}
i_{a s} \\
i_{b s} \\
i_{c s}
\end{array}\right] .
\end{aligned}
$$

In order to achieve linear transformation in modeling, analysis, and simulations, the power input to the three-phase machine has to be equal to the power input to the two-phase machine.

The $d$ - and $q$-axes currents in the rotor frame of reference are obtained as [10]

$$
\left[\begin{array}{l}
i_{d s}^{r}=i_{f} \\
i_{q s}^{r}=i_{T}
\end{array}\right]=i_{s}\left[\begin{array}{l}
\cos \delta \\
\sin \delta
\end{array}\right]=\left[\begin{array}{l}
0 \\
i_{s}
\end{array}\right],
$$

where " $i_{f}$ " is the flux producing and " $i_{T}$ " is the torque producing component.

Electromagnetic torque is the most important variable as it determines the rotor position and speed. The expression for the electromagnetic torque developed by the machine can be obtained from the input power and other quantities as given in the following [11]:

$$
T_{e}=\frac{3}{2} \frac{P}{2}\left[\lambda_{\mathrm{af}}+\left(L_{d}-L_{q}\right) i_{d s}^{r}\right] i_{q s}^{r} .
$$

By substituting the value of $i_{d s}^{r}$ and $i_{q s}^{r}$ from (6), (7) can be expressed as

$$
T_{e}=\frac{3}{2} \frac{P}{2}\left[\lambda_{\mathrm{af}}+\left(L_{d}-L_{q}\right) i_{s} \cos \delta\right] i_{s} \sin \delta .
$$

From (8), it can be seen that the air gap torque is the sum of reluctance torque $\left(T_{e r}\right)$ and synchronous torque $\left(T_{e s}\right)$. From the loci (refer to Figure 1), it is observed that the peak of air gap torque $\left(T_{e}\right)$ occurs at an angle between $90^{\circ}$ and $180^{\circ}$ and reduces between $0^{\circ}$ and $90^{\circ}$. Hence, the preferred angle is $90^{\circ}<\delta<180^{\circ}[10]$.

\section{Control Strategies for PMSM}

The most commonly used five different control strategies applicable to PM synchronous machines are discussed in this section:

(1) Constant torque angle control (CTAC).

(2) Optimum torque per ampere control (OTPAC).

(3) Unity power factor control (UPFC).

(4) Constant mutual air gap flux linkages control (CMFLC). 


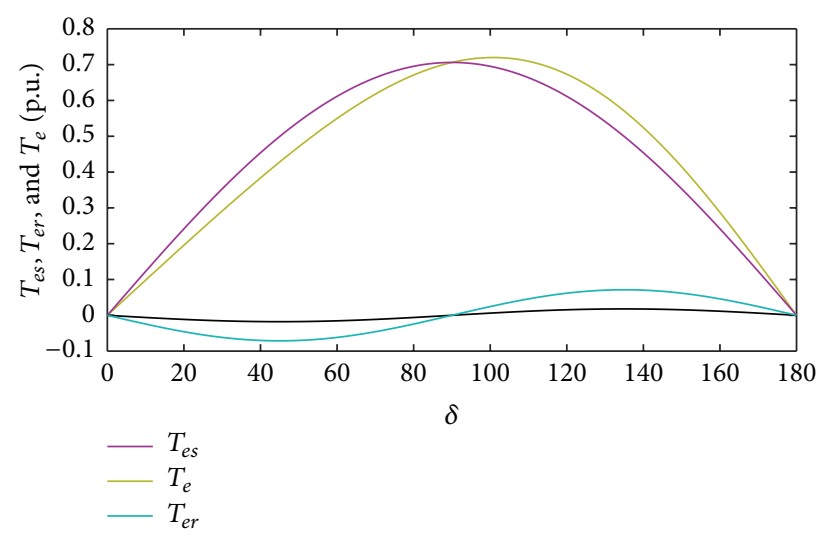

FIGURE 1: Synchronous, reluctance, and air gap torques versus torque angle $(\delta)$.

(5) Angle control of air gap flux and current phasors (ACAGF).

Such control strategies are important as they provide a wide variation of control choices in many applications. To obtain better performance, these control strategies are analyzed and derived step by step for the steady-state operations only where the state rate of change of current is zero.

3.1. Constant Torque Angle Control. In this control strategy, the torque angle $(\delta)$ which is the angle between the rotor field and current phasor is maintained at $90^{\circ}$. Hence, by maintaining $\delta=90^{\circ}$ from (6), we can conclude that the flux producing component is equal to 0 and the torque producing component is equal to the supply current making PMSM operate like a separately excited DC machine [7]. Therefore, this strategy is also referred to as zero direct axis current (ZDAC) control. The main advantage of ZDAC control strategy is that it gives the simplest and easiest control for PMSM.

Hence, the following relevant equations hold for this strategy is derived in the following.

Since $i_{d s}^{r}=0$, from (6) and (7), the electromagnetic torque becomes

$$
T_{e}=\frac{3}{2} \frac{P}{2} \lambda_{\mathrm{af}} i_{q s}^{r}=\frac{3}{2} \frac{P}{2} \lambda_{\mathrm{af}} i_{s} .
$$

From (1) and (2), the steady-state $d$ - and $q$-axes stator voltages are

$$
\begin{aligned}
& v_{d s}^{r}=-\omega_{r} L_{q} i_{s}, \\
& v_{q s}^{r}=\left(R_{s}+L_{q} p\right) i_{s}+\omega_{r} \lambda_{\mathrm{af}} .
\end{aligned}
$$

3.2. Optimum Torque per Ampere Current Control. This strategy is one of the most widely used control strategies for PMSM [12-16]. Application of the optimum torque per ampere (OTPA) control strategy ensures maximum torque for a minimum possible value of current which in turn minimizes the ohmic losses [17-24]. The mathematical model of this strategy is developed as follows. Consider the electromagnetic torque equation of PMSM given in (8):

$$
\begin{aligned}
T_{e} & =\frac{3}{2} \frac{P}{2}\left[\lambda_{\mathrm{af}}+\left(L_{d}-L_{q}\right) i_{s} \cos \delta\right] i_{s} \sin \delta, \\
T_{e} & =\frac{3}{2} \frac{P}{2}\left[\lambda_{\mathrm{af}} i_{s} \sin \delta+\left(L_{d}-L_{q}\right) i_{s}^{2} \cos \delta \sin \delta\right], \\
T_{e} & =\frac{3}{2} \frac{P}{2}\left[\lambda_{\mathrm{af}} i_{s} \sin \delta+\frac{1}{2}\left(L_{d}-L_{q}\right) i_{s}^{2} \sin 2 \delta\right] .
\end{aligned}
$$

The normalized torque expression can be obtained as

$$
\begin{aligned}
& T_{e n}=\frac{T_{e}}{T_{b}} \\
& =\frac{(3 / 2)(P / 2)\left[\lambda_{\mathrm{af}} i_{s} \sin \delta+(1 / 2)\left(L_{d}-L_{q}\right) i_{s}^{2} \sin 2 \delta\right]}{(3 / 2)(P / 2) \lambda_{\mathrm{af}} I_{b}}, \\
& T_{e n}=\frac{i_{s}\left[\lambda_{\mathrm{af}} \sin \delta+(1 / 2)\left(L_{d}-L_{q}\right) i_{s} \sin 2 \delta\right]}{\lambda_{\mathrm{af}} I_{b}} .
\end{aligned}
$$

Let $\lambda_{\text {af }}=I_{b} L_{b}, i_{s n}=i_{s} / I_{b}, L_{d n}=L_{d} / L_{b}$, and $L_{q n}=L_{q} / L_{b}$.

Rewrite (12) as follows:

$$
T_{e n}=i_{s n}\left[\sin \delta+\frac{1}{2}\left(L_{d n}-L_{q n}\right) i_{s n} \sin 2 \delta\right] .
$$

From (13), the torque per unit stator current is defined as

$$
\frac{T_{e n}}{i_{s n}}=\left[\sin \delta+\frac{1}{2}\left(L_{d n}-L_{q n}\right) i_{s n} \sin 2 \delta\right] .
$$

The torque angle where the PMSM produces maximum torque per unit stator current is obtained by differentiating (14) with respect to $\delta$ and equating it to zero; that is, the following equation should be satisfied [8]:

$$
\frac{d}{d \delta}\left[\sin \delta+\frac{1}{2}\left(L_{d n}-L_{q n}\right) i_{s n} \sin 2 \delta\right]=0 .
$$

The solution of the above equation gives

$$
\left\{\cos \delta+\frac{1}{2}\left(L_{d n}-L_{q n}\right) i_{s n} 2 \cos 2 \delta\right\}=0 .
$$

Using the double-angle identities, $\cos (2 \delta)=2 \cos ^{2}(\delta)-1$ in (16) can be rewritten as

$$
\begin{aligned}
& \{\cos \delta \\
& \left.\quad+\frac{1}{2}\left(L_{d n}-L_{q n}\right) i_{s n}\left[\cos (2 \delta)=2 \cos ^{2}(\delta)-1\right]\right\} \\
& =0 .
\end{aligned}
$$

Solving (17) for $\delta$ gives

$$
\begin{aligned}
\delta & =\cos ^{-1}\left\{\frac{-1}{4\left(L_{d n}-L_{q n}\right) i_{s n}}\right. \\
& \left. \pm \sqrt{\frac{1}{2}+\left[\frac{1}{4\left(L_{d n}-L_{q n}\right) i_{s n}}\right]^{2}}\right\} .
\end{aligned}
$$


In (18), $90^{\circ}<\delta<180^{\circ}$ so as to minimize field in the air gap; hence, only positive sign is considered [7].

Finally, the expression for torque angle is given as

$$
\begin{aligned}
\delta= & \cos ^{-1}\left\{\frac{-1}{4\left(L_{d n}-L_{q n}\right) i_{s n}}\right. \\
& \left.+\sqrt{\frac{1}{2}+\left[\frac{1}{4\left(L_{d n}-L_{q n}\right) i_{s n}}\right]}\right\} .
\end{aligned}
$$

3.3. Unity Power Factor Control. Power factor can be defined as the cosine of the phase angle between voltage and current as given in the following:

$$
\text { p.f. }=\cos \phi
$$

where p.f. is the power factor and " $\phi$ " denotes the angle between voltage and current. In some applications, the main goal is to have a unity power factor during the operation of motor [25-27]. Unity power factor control implies the volt ampere (VA) requirement of the inverter can be reduced by maintaining the power factor at unity [28]. The performance equations in this strategy are derived and given below.

In UPF control strategy, the phase angle has to be zero which implies the following relationship:

$$
\tan \delta=\frac{v_{q s}^{r}}{v_{d s}^{r}}=\frac{i_{q s}^{r}}{i_{d s}^{r}}
$$

Substituting (1), (2), and (6) into (21) results in

$$
\begin{aligned}
& \tan \delta=\frac{\left(R_{s}+L_{q} p\right) i_{q s}^{r}+\omega_{r}\left(L_{d} i_{d s}^{r}+\lambda_{\mathrm{af}}\right)}{\left(R_{s}+L_{d} p\right) i_{d s}^{r}-\omega_{r} L_{q} i_{q s}^{r}}, \\
& \tan \delta=\frac{\left(R_{s}+L_{q} p\right) i_{s} \sin \delta+\omega_{r}\left(L_{d} i_{s} \cos \delta+\lambda_{\mathrm{af}}\right)}{\left(R_{s}+L_{d} p\right) i_{s} \cos \delta-\omega_{r} L_{q} i_{s} \sin \delta}, \\
& \tan \delta=\frac{R_{s} i_{s} \sin \delta+\omega_{r} L_{d} i_{s} \cos \delta+\omega_{r} \lambda_{\mathrm{af}}}{R_{s} i_{s} \cos \delta-\omega_{r} L_{q} i_{s} \sin \delta} \\
& \frac{\sin \delta}{\cos \delta}=\frac{1+L_{d n} i_{s n} \cos \delta+\left(R_{s n} i_{s n} / \omega_{r n}\right) \sin \delta}{R_{s n} i_{s n} \cos \delta / \omega_{r n}-L_{q n} i_{s n} \sin \delta} .
\end{aligned}
$$

Solving for $\delta$,

$$
\delta=\cos ^{-1}\left\{\frac{-1+\sqrt{1-4 L_{q n} i_{s n}^{2}\left(L_{d n}-L_{q n}\right)}}{2 i_{s n}\left(L_{d n}-L_{q n}\right)}\right\} .
$$

From (23), it is evident that $\delta$ is independent of rotor speed. Positive sign in (23) and $\left(L_{d n}<L_{q n}\right)$ should be considered so as to utilize maximum possible torque under UPF control strategy [29].

3.4. Constant Mutual Flux Linkages Control. In constant mutual flux linkage control (CMFLC), the mutual flux linkages are maintained constant and usually set equal to rotor flux linkages. The reason behind this is that machine is protected against magnetic saturation [30]. Limiting the mutual flux linkages, the stator voltage requirement can be kept consonantly low. This is the main advantage of CMFL strategy. In addition, for the speeds higher than base speed, this strategy provides flux weakening as compared to the other schemes that are limited for operation at speeds lower than the base speed [31]. In this case, the magnitude of mutual flux linkage is expressed as follows:

$$
\lambda_{m}=\sqrt{\left(\lambda_{d s}^{r}+\lambda_{q s}^{r}\right)^{2}}=\sqrt{\left(\lambda_{\mathrm{af}}+L_{d} i_{d s}^{r}\right)^{2}+\left(L_{q} i_{q s}^{r}\right)^{2}} .
$$

In (24), the magnitude of mutual flux linkage is kept constant and equal to $\lambda_{\mathrm{af}}$. Also, substituting (6) into (24) gives

$$
\begin{aligned}
& \lambda_{\mathrm{af}}=\sqrt{\left(\lambda_{\mathrm{af}}+L_{d} i_{s} \cos \delta\right)^{2}+\left(L_{q} i_{s} \sin \delta\right)^{2}}, \\
& \lambda_{\mathrm{af}}^{2}=\left(\lambda_{\mathrm{af}}+L_{d} i_{s} \cos \delta\right)^{2}+\left(L_{q} i_{s} \sin \delta\right)^{2} .
\end{aligned}
$$

Using the formulae, $a^{2}+b^{2}=(a+b)^{2}-2 a b$ in (26) can be rewritten as

$$
\begin{aligned}
= & {\left[\left(\lambda_{\mathrm{af}}+L_{d} i_{s} \cos \delta\right)+\left(L_{q} i_{s} \sin \delta\right)\right]^{2}-2\left(\lambda_{\mathrm{af}}\right.} \\
& \left.+L_{d} i_{s} \cos \delta\right)\left(L_{q} i_{s} \sin \delta\right)=\left[\left(\lambda_{\mathrm{af}}+L_{d} i_{s} \cos \delta\right)^{2}\right. \\
& \left.+2\left(\lambda_{\mathrm{af}}+L_{d} i_{s} \cos \delta\right)\left(L_{q} i_{s} \sin \delta\right)+\left(L_{q} i_{s} \sin \delta\right)^{2}\right] \\
& -2\left(\lambda_{\mathrm{af}}+L_{d} i_{s} \cos \delta\right)\left(L_{q} i_{s} \sin \delta\right) .
\end{aligned}
$$

Using trigonometric-Pythagorean identities, that is, $\cos ^{2} \delta+$ $\sin ^{2} \delta=1$, the above equation can be rewritten as

$$
2 \lambda_{\mathrm{af}} L_{d} i_{s} \cos \delta+\left(L_{d} i_{s} \cos \delta\right)^{2}+\left(L_{q} i_{s} \sin \delta\right)^{2}=0 .
$$

In order to determine the magnitude of $\delta$, two different cases arise depending upon the saliency ratio, that is, $L_{q} / L_{d}$.

Case 1 (for surface mounted PMSM $L_{q} / L_{d}=1$ ). Solving (28) for $\delta$ yields

$$
\delta=\cos ^{-1}\left\{\frac{-L_{d} i_{s}}{2 \lambda_{\mathrm{af}}}\right\} .
$$

In normalized form, the torque angle $\delta$ is derived as

$$
\delta=\cos ^{-1}\left\{-\frac{i_{s} L_{d}}{2 I_{b} L_{b}}\right\}=\cos ^{-1}\left\{-\frac{i_{s n} L_{d n}}{2}\right\},
$$

where $\lambda_{\mathrm{af}}=I_{b} L_{b}$. 
Case 2 (for interior mounted PMSM $L_{q} / L_{d} \neq 1$ ). Solving (28) for $\delta$ yields

$$
\begin{aligned}
\delta & =\cos ^{-1}\left\{\frac{1}{L_{d n} i_{s n}\left[1-\left(L_{q} / L_{d}\right)^{2}\right]}\right. \\
& \pm \sqrt{\left.\left\{\frac{1}{L_{d n}\left[1-\left(L_{q} / L_{d}\right)^{2}\right] i_{s n}}\right\}-\frac{1}{\left[1-\left(L_{q} / L_{d}\right)^{2}\right]}\right\} .}
\end{aligned}
$$

For CMFLC strategy, $\delta$ has to be greater than $90^{\circ}$. The CMFLC is preferred over UPF control strategy as it provides significant torque [32].

3.5. Angle Control of Air Gap Flux and Current Phasors. In this strategy, the air gap torque expression may be derived as follows.

Consider (7)

$$
\begin{aligned}
T_{e} & =\frac{3}{2} \frac{P}{2}\left[\lambda_{\mathrm{af}}+\left(L_{d}-L_{q}\right) i_{d s}^{r}\right] i_{q s}^{r} \\
& =\frac{3}{2} \frac{P}{2}\left[\lambda_{\mathrm{af}} i_{q s}^{r}+\left(L_{d}-L_{q}\right) i_{d s}^{r} i_{q s}^{r}\right] .
\end{aligned}
$$

The above equation can be written in the following form:

$$
T_{e}=\frac{3}{2} \frac{P}{2}\left[\lambda_{\mathrm{af}} i_{q s}^{r}+L_{d} i_{d s}^{r} i_{q s}^{r}-L_{q} i_{d s}^{r} i_{q s}^{r}\right]
$$

Rearrange (33) as follows:

$$
T_{e}=\frac{3}{2} \frac{P}{2}\left[\left(\lambda_{\mathrm{af}}+L_{d} i_{d s}^{r}\right) i_{q s}^{r}-L_{q} i_{d s}^{r} i_{q s}^{r}\right]
$$

From (24) and (6), the above expression can be written in the following form:

$$
T_{e}=\frac{3}{2} \frac{P}{2}\left[\lambda_{d s}^{r} i_{q s}^{r}-\lambda_{q s}^{r} i_{d s}^{r}\right]=\frac{3}{2} \frac{P}{2} \lambda_{m} i_{s} \sin \theta_{m s},
$$

where $\lambda_{d s}^{r}=\lambda_{m} \cos \theta_{m s}$ and $\lambda_{q s}^{r}=\lambda_{m} \sin \theta_{m s}$.

Also, angle between the air gap flux phasor and current is $\theta_{m s}=\delta-\theta_{\lambda}$.

The air gap flux of PMSM cannot be kept constant for all values of current. So the main concept of this strategy is to maintain $\theta_{m s}$ at $90^{\circ}$ which is analogous to the control of separately excited DC machine [33]. This is the main advantage of this strategy as it permits a simple control without a position sensor. The drawback with this strategy is that it cannot be used in the applications where low/zero speed is required as the magnitude of induced emf is very low [10].

\section{Simulation Studies and Discussion}

The performance characteristics of PMSM under different control strategies for rated speed (1 p.u.) are realized in

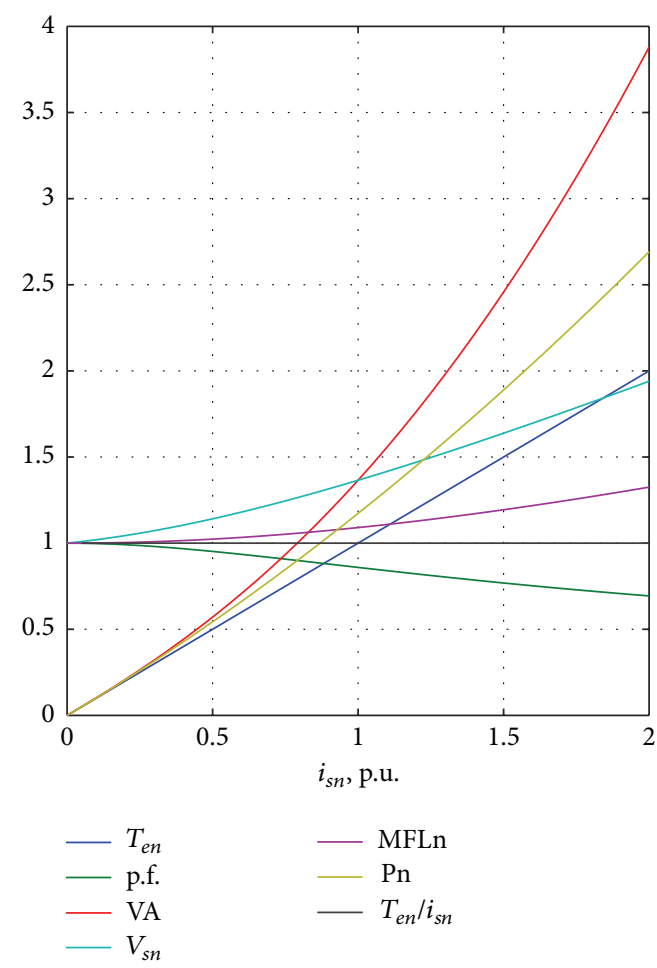

FIGURE 2: Performance characteristics of PMSM for constant torque angle control.

MATLAB environment. Simulation results for five control strategies under which PMSM is operating are presented ahead. The plotted variables are in normalized units (p.u.). The parameters and rating of PMSM used to plot the curves in the simulation are given in the Appendix. Also, all the chosen quantities such as power factor, stator voltage required electromagnetic torque, apparent power, mutual flux linkage, and input power are plotted on the same scale.

4.1. Constant Torque Angle Control. The performance characteristics for this control strategy are shown in Figure 2. From Figure 2, it is observed that the power factor $(\cos \phi)$ deteriorates as the stator current rises. The normalized stator voltage $\left(V_{s n}\right)$ required to drive the motor in this control strategy is presented in the following figure. Under this control strategy, the PMSM is able to produce a torque up to 2 p.u. The torque versus stator current curve shows that the electromagnetic torque $\left(T_{e n}\right)$ is directly proportional to the magnitude of stator current which is analogous to DC motor. Also, from the normalized mutual flux linkage (MFLn) characteristics, it is seen that it cannot reduce below 1 p.u. but can vary from 1 p.u. to a point greater than 1 p.u. This is only possible till torque angle is kept constant at $90^{\circ}$ [7]. Due to this, it is limited to the applications which do not require flux weakening operation. In addition, the apparent power (VA) is also plotted so as to evaluate the VA rating requirement of the inverter.

4.2. Optimum Torque per Unit Current Control. Figure 3 plots the optimum torque per ampere (OTPA) locus which appears 


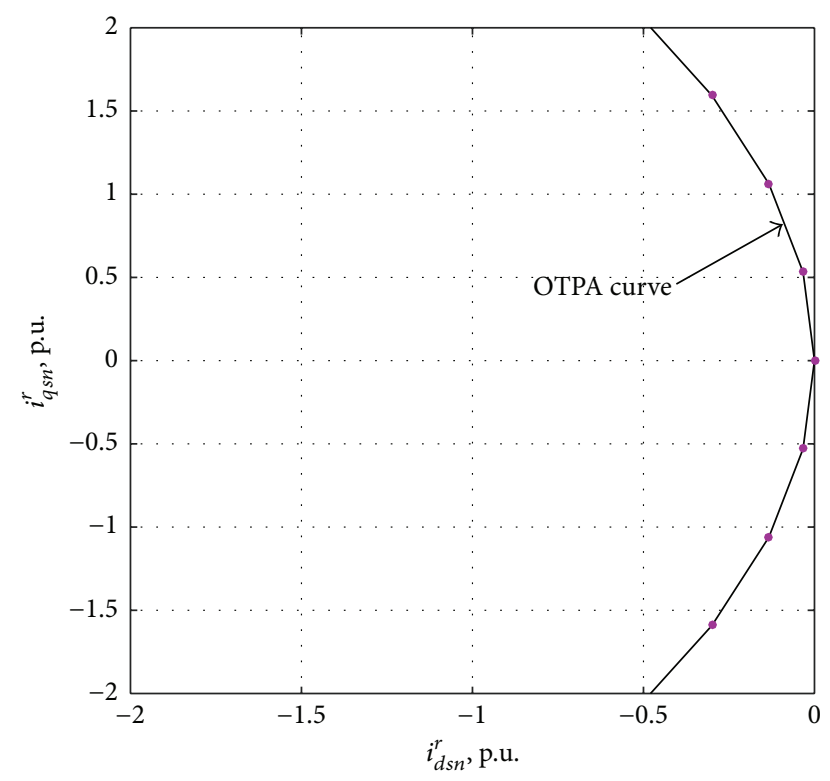

FIgURE 3: OTPA locus in $i_{d s}^{r}$ and $i_{q s}^{r}$ frame.

like a hyperbola in the rotor $i_{d s}^{r}$ and $i_{q s}^{r}$ frame. For plotting the OTPA locus for different values of commanded torque, the $q$ axis current is calculated first. Then, from (7), it is observed that $d$-axis current is the function of $q$-axis current from which the $d$-axis current is determined. These minimum current points for a given torque when connected together make a hyperbola which is referred to as OTPA trajectory. In determining the curves of Figure 4, it has been assumed the difference $\left(L_{d n}-L_{q n}\right)$ should be positive. The magnitude of $T_{e n}$ is proportional to $i_{s n}$. The $T_{e n} / i_{s n}$ envelope for this strategy is slightly higher than unity. The OTPAC strategy results in reasonable p.f. varying from unity to roughly 0.65 .

4.3. Unity Power Factor Control. Figure 5 shows the performance characteristics with the UPF control strategy.

Power versus current envelope shows the real power at any value of stator current. At the beginning, $T_{e n}$ increases with the increase in $i_{s n}$ and attains to its peak value $T_{e n}(\max )$ at $i_{s n}(\max )$. Afterwards, if $i_{s n}$ is increased further beyond $i_{s n}(\max ), T_{e n}(\max )$ decreases. Also, the magnitude of $V_{s n}$ is decreasing with increase in the value of $i_{s n}$. But from the plot of $T_{e n} / i_{s n}$, it is seen that its value is less than 1 , indicating that UPF control is not optimum in terms of torque generation as the maximum torque offered in this control is smaller when compared to other control methods. This feature is needed in applications demanding extended speed range.

4.4. Constant Mutual Flux Linkages Control. The performance characteristics of constant mutual flux linkages control for surface mounted (SM) and interior mounted (IM) PMSM are shown in Figures 6 and 7, respectively. On limiting the magnitude of mutual flux linkage to the rotor permanent magnet flux, the torque producing capability of PMSM is also limited. For the SMPMSM, $V_{s n}$ is maintained approximately

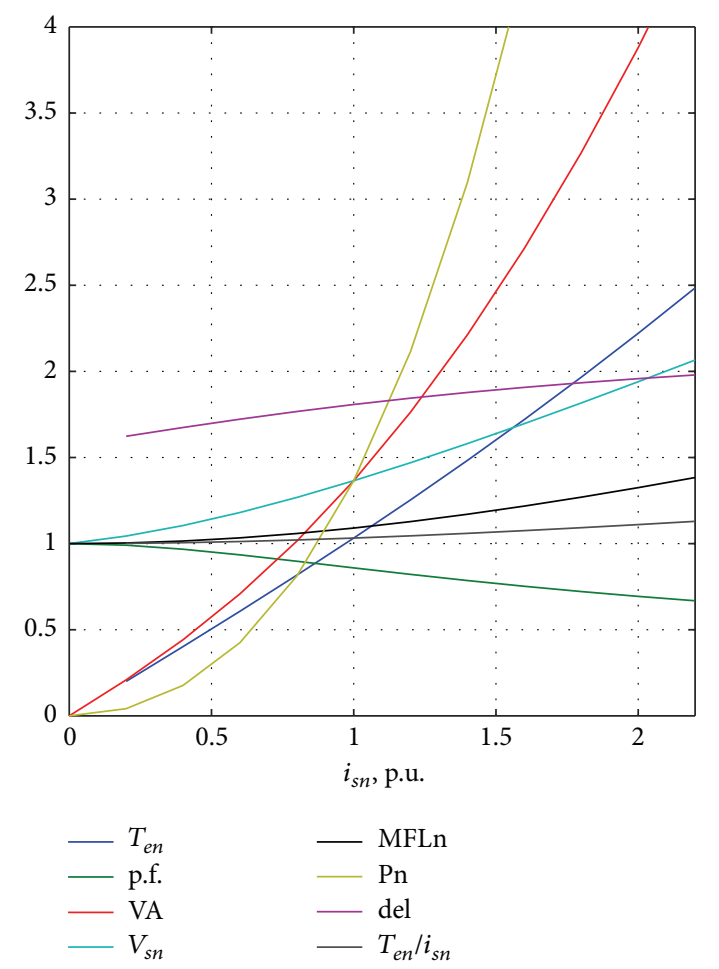

FIgURE 4: Performance characteristics of PMSM for optimum torque per unit current control.

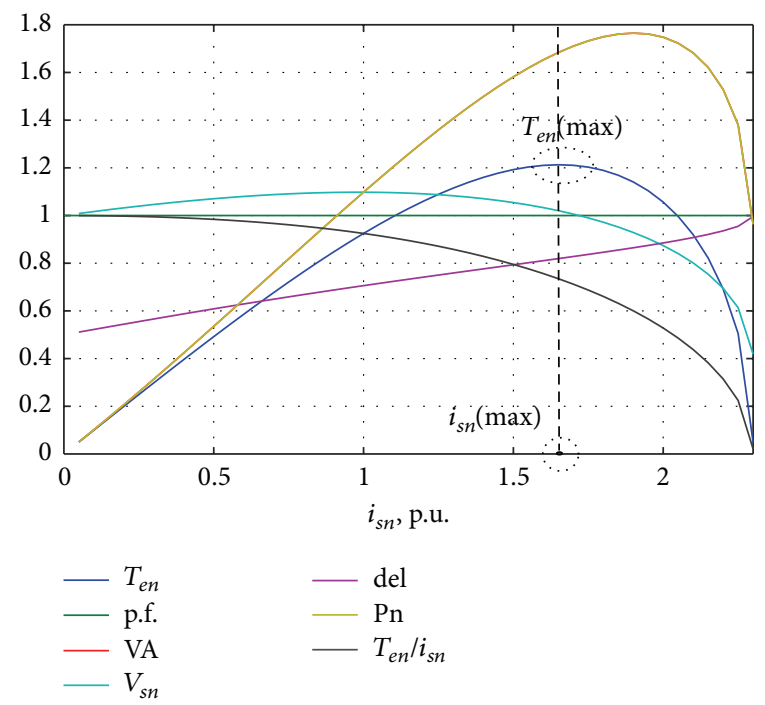

FIgURE 5: Performance characteristics of PMSM for $\cos \phi=1$ control.

constant while, for IMPMSM, $V_{s n}$ increases with $i_{s n}$. Also, from Figures 6 and 7, it is observed from the characteristics of p.f. that it is near to unity up to 1 p.u. of $i_{s n}$. This indicates that the CMFLC is closer to unity power factor when compared with CTAC where the p.f. is near to unity up to 0.25 p.u. of $i_{s n}$. The ratio of normalized torque per unit to normalized stator current $\left(T_{e n} / i_{s n}\right)$ is decreasing but offers significant $T_{e n}$ over a greater current range when compared to the UPFC strategy. 


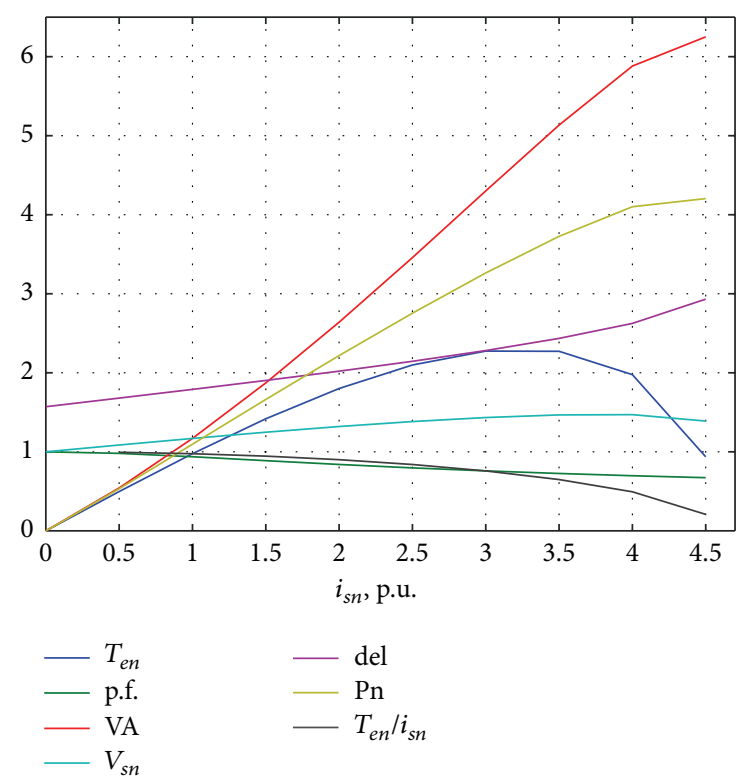

FIgURE 6: Performance characteristics of constant mutual air gap flux linkages control for SMPMSM.

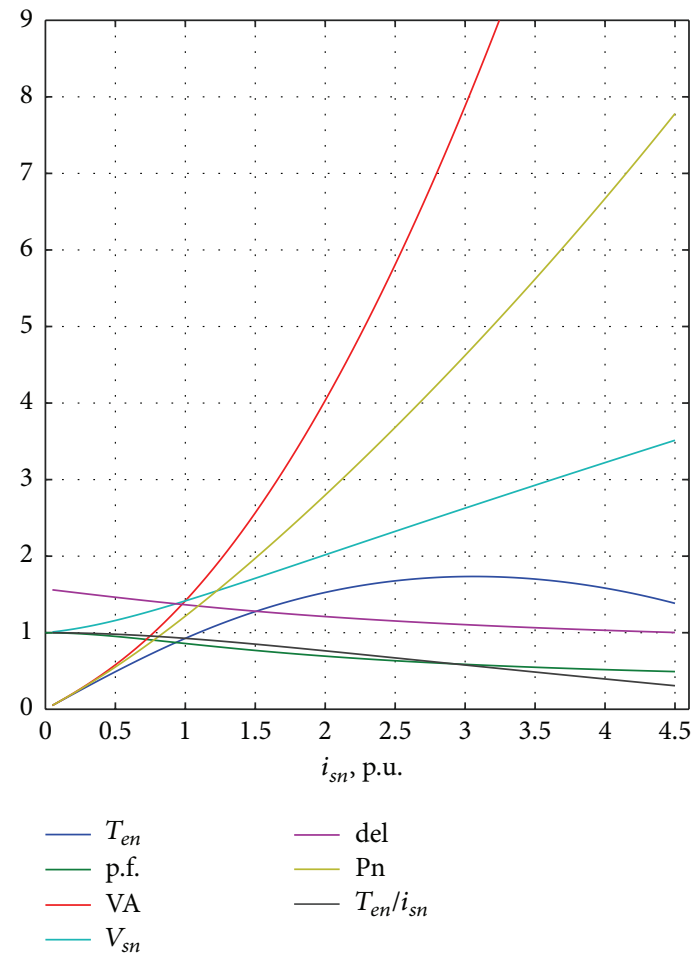

Figure 7: Performance characteristics of constant mutual air gap flux linkages control for IMPMSM.

4.5. Angle Control of Air Gap Flux and Current Phasors. The performance characteristics of angle control of air gap flux and current phasors for PMSM are shown in Figure 8. The salient feature of this strategy is that VA requirement is low as MFLn is decreasing with the increase in magnitude of stator current. Decrease in MFLn with the increase in magnitude

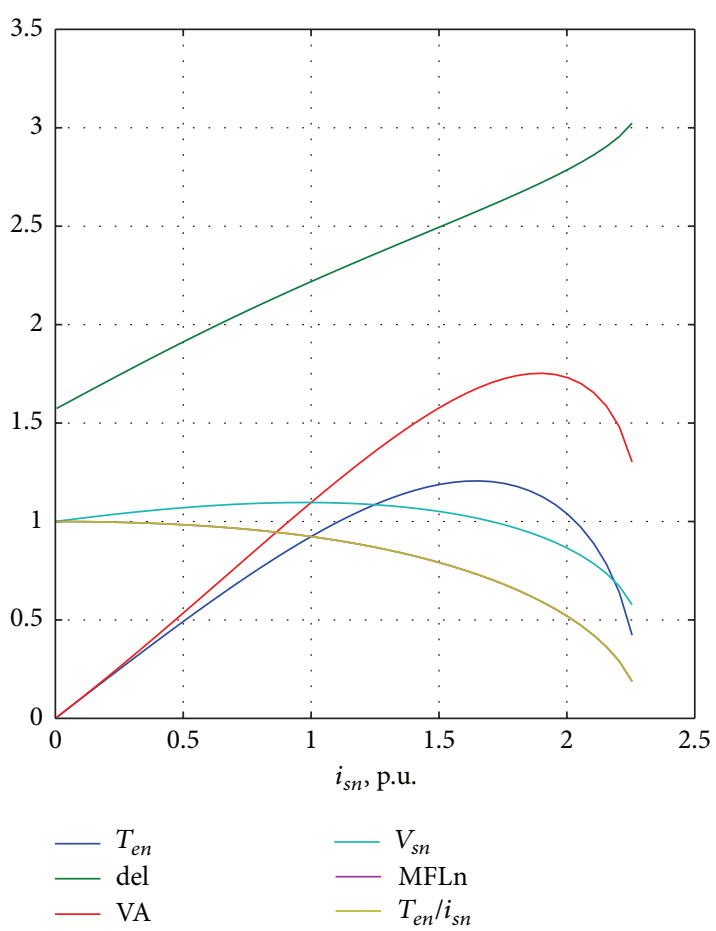

FIgURE 8: Performance characteristics of PMSM for angle control of air gap flux and current phasor.

of stator current also limits the requirement of stator voltage $\left(V_{s n}\right)$ [10]. The ratio $T_{e n} / i_{s n}$ is less than 1 , indicating that ACAGF control is not optimal in terms of torque generation. All these features and characteristics closely resemble the characteristics of unity power factor control strategy.

\section{Comparison of Control Strategies}

For constant torque angle control, optimum torque per ampere current control, unity power factor control, constant mutual air gap flux linkages control, and angle control of air gap flux and current phasors, the different quantities versus torque are plotted and realized in MATLAB environment to compare the performances of these control strategies. The following simulation results presented ahead give comparisons between these control strategies for the most important characteristics, that is, current, voltage, VA rating, and power factor requirement versus normalized torque for rated speed (1 p.u.). This study will help to select the optimal control strategy depending upon the requirements.

5.1. Current Requirement as a Function of Torque. The performance characteristics of current requirement for different control strategies as a function of torque are shown in Figure 9. It should be noted that the OTPAC needs the minimum possible value of current for a given value of torque when compared with CTAC, UPFC, CMFLC, and ACAGF as expected. However, for all these five strategies, there is no major difference for the requirement of current up to 1 p.u. of $T_{e n}$. Furthermore, it can be observed from the plot of 


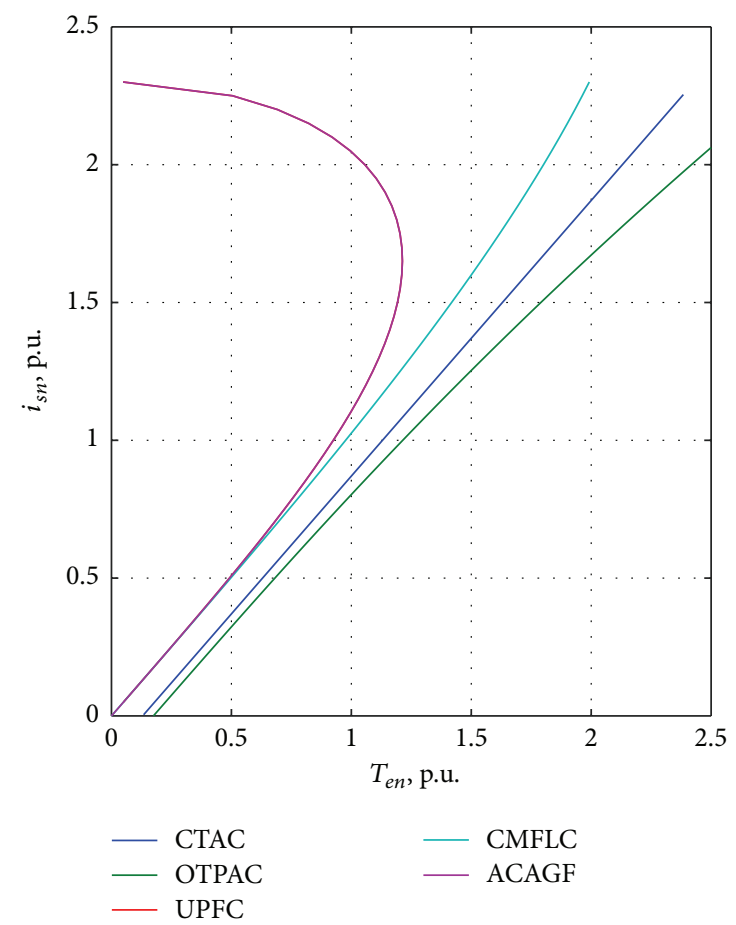

FIGURE 9: Current requirement for five different control strategies as a function of normalized torque.

UPFC that, for each value of torque, there exist two operating points. But the points with lower current requirement are considered rather than points with higher current due to the current limitations [29], though the UPF needs the maximum possible value of current for a given value of torque higher than 0.5 p.u. when compared with CTAC, OTPAC, CMFLC, and ACAGF.

5.2. Voltage Requirement as a Function of Torque. The performance characteristics of voltage requirement for different control strategies as a function of torque are shown in Figure 10.

It should be noted that the voltage requirement for CTAC strategy is the highest, whereas for both UPFC and ACAGF it is the lowest.

5.3. VA Rating Requirement as a Function of Torque. The performance characteristics of volt ampere requirement for different control strategies as a function of torque are shown in Figure 11.

The comparison clearly reveals that the volt ampere requirement for CTAC strategy is the highest whereas for both UPFC and ACAGF it is the lowest. This is because the current and voltage requirement for CTAC are the highest and VA is the product of both. Also, the volt ampere requirement for CMFLC strategy is the lowest when compared with CTAC and OTPAC. However, all strategies approximately require the same volt ampere up to 1 p.u. of $T_{e n}$; after that, the requirements diverge significantly. Again, from the plot of UPFC, it can be observed that for each value of torque there

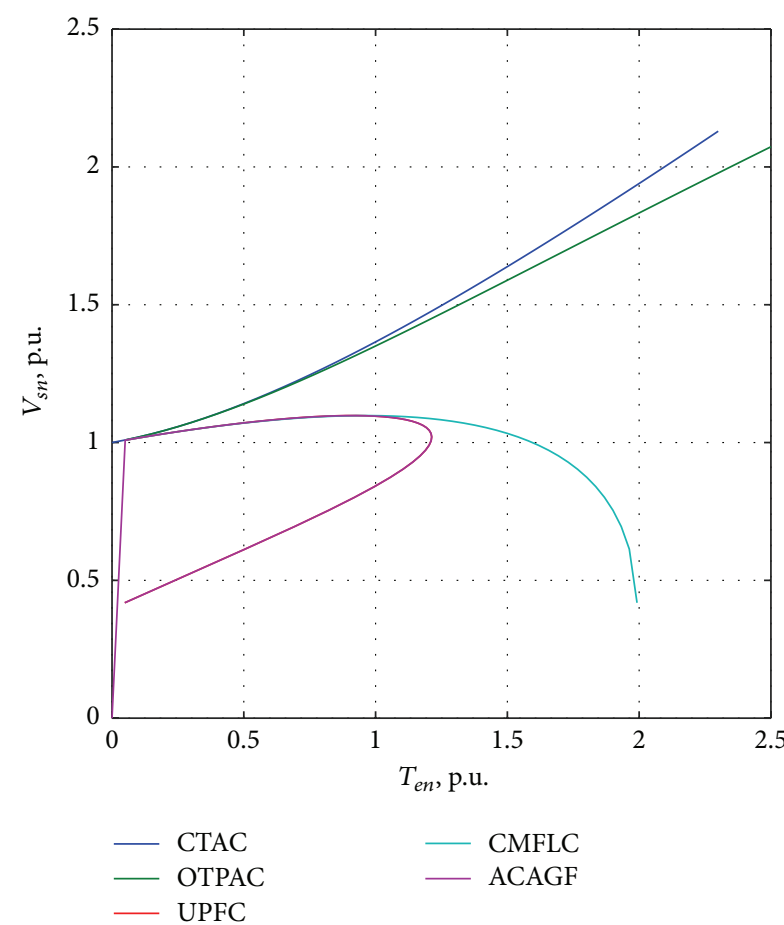

FIGURE 10: Voltage requirement for five different control strategies as a function of normalized torque.

exist two operating points for volt ampere requirement. But the points with lower VA requirement are considered due to the current limitations.

5.4. Variation of Power Factor Requirement as a Function of Torque. The performance characteristics of power factor requirement for different control strategies as a function of torque are shown in Figure 12. The UPFC strategy yields unity power factor whereas for CTAC strategy it falls rapidly roughly around 0.68 to 0.64 when compared with OTPAC and CMFLC as the torque increases. Power factor requirement for CMFLC and OTPAC is next to UPFC [29].

\section{Conclusion}

In this paper, different control strategies for PMSM are derived and presented in detail. The study based on the simulation results reveals that OTPAC is superior in $\left(T_{e n} / i_{s n}\right)$ ratio among the five different control strategies whereas the UPF control yields a very low $\left(T_{e n} / i_{s n}\right)$ ratio. Also, all the performance characteristics for each strategy shown above are compared. And the comparative analysis reveals that the main advantage with UPFC is the voltage requirement which is comparatively low but the drawback lies in torque production in the PMSM which is about 1.2 p.u. On comparing UPFC with CMFLC, it should be noted that the voltage requirement for CMFLC is next to UPFC but can produce much higher electromagnetic torque. Finally, from the above comparative study, it can be concluded that the CMFLC has better steady-state performance characteristics and it can be 


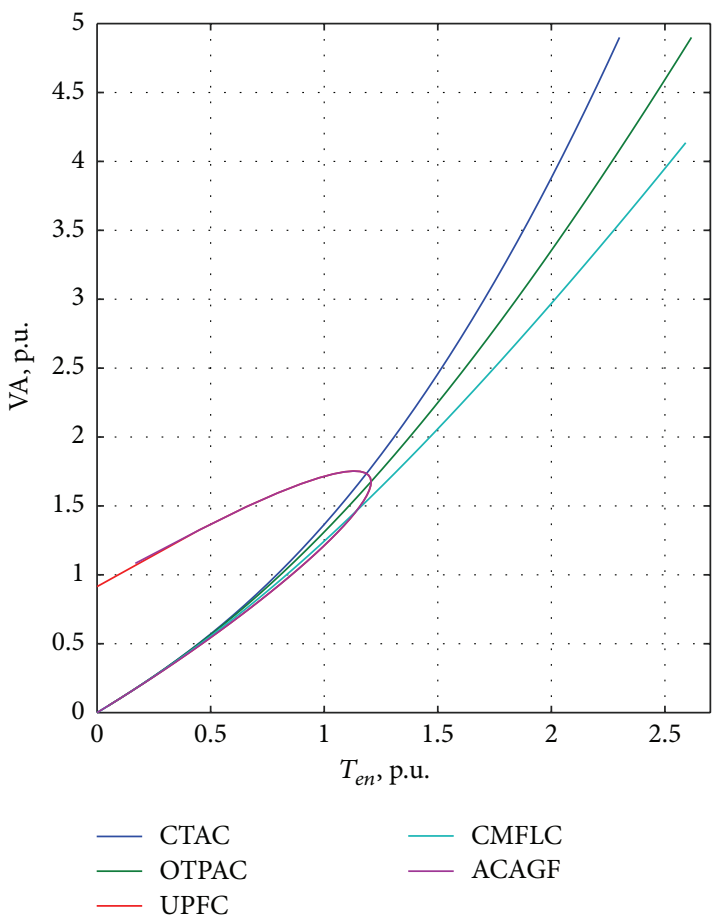

FIGURE 11: VA requirement for five different control strategies as a function of normalized torque.

a good control strategy to consider when compared to the OTPAC, CTAC, UPFC, and ACAGF.

\section{Appendix}

$$
\begin{aligned}
& R_{s n}=0.1729 \text { p.u. } \\
& L_{d n}=0.4347 \text { p.u. } \\
& L_{q n}=0.6986 \text { p.u. } \\
& L_{b}=0.0129 \mathrm{H} \\
& V_{b}=97.138 \mathrm{~V} \\
& I_{b}=12 \mathrm{~A} \\
& \omega_{b}=628.6 \mathrm{rad} / \mathrm{s} \\
& J=0.0012 \mathrm{~kg} \cdot \mathrm{m}^{2} \\
& B=0.01 \mathrm{~N} \cdot \mathrm{m} \cdot \mathrm{s} / \mathrm{rad} \\
& P=6 \\
& T_{b}=5.5631 \mathrm{~N} \cdot \mathrm{m} \\
& V_{\mathrm{dc}}=285 \mathrm{~V}(\mathrm{bus} \mathrm{voltage})
\end{aligned}
$$

Power $=3.5 \mathrm{~kW}$

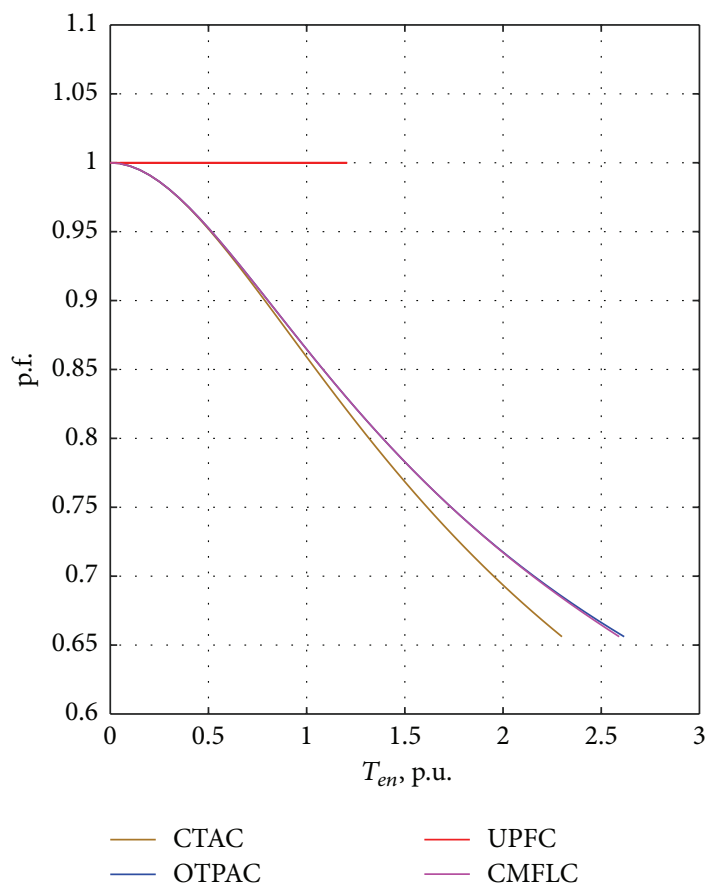

FIGURE 12: Power factor requirement for four different control strategies as a function of normalized torque.

\section{Nomenclature}

$B: \quad$ Damping constant, $(\mathrm{N} / \mathrm{rad} / \mathrm{s})$

$i_{d s}^{r}, i_{q s}^{r}: \quad d$ - and $q$-axes stator currents in rotor reference frame, (A)

$i_{a s}, i_{b s}, i_{c s}:$ Instantaneous stator phase currents, (A)

$i_{s}: \quad$ Stator current magnitude, (A)

$I_{b}: \quad$ Base current, $(\mathrm{A})$

J: $\quad$ Total moment of inertia, $\left(\mathrm{kgm}^{2}\right)$

$L_{d}, L_{q}: \quad$ Stator $d$ - and $q$-axes self-inductances, $(\mathrm{H})$

$L_{d n}, L_{q n}: \quad$ Normalized stator $d$ - and $q$-axes

self-inductances, $(\mathrm{H})$

$L_{b}: \quad$ Base inductance, $(\mathrm{H})$

$P: \quad$ Number of poles

$R_{s}: \quad$ Stator resistance per phase, $(\Omega)$

$T_{e}: \quad$ Electromagnetic torque, $(\mathrm{N} \cdot \mathrm{m})$

$T_{e n}: \quad$ Normalized electromagnetic torque, (p.u.)

$T_{l}: \quad$ Load torque, $(\mathrm{N} \cdot \mathrm{m})$

$T_{b}: \quad$ Base torque, $(\mathrm{N} \cdot \mathrm{m})$

$\delta: \quad$ Torque angle

$\lambda_{\mathrm{af}}: \quad$ Armature flux linkages, $(\mathrm{V} \cdot \mathrm{s})$

$\lambda_{m}: \quad \quad$ Mutual flux linkages, $(\mathrm{V} \cdot \mathrm{s})$

p: $\quad$ Differential operator, $d / d t$

$V_{s}: \quad$ Stator voltage phasor magnitude, $(\mathrm{V})$

$v_{a s}, v_{b s}, v_{c s}:$ Input phase voltages, (V)

$v_{d s}^{r}, v_{q s}^{r}: \quad d$ - and $q$-axes stator voltages in rotor reference frame, $(\mathrm{V})$

$\theta_{r}: \quad$ Actual rotor position, (radians)

$\theta_{\lambda}$ : Angle between the mutual flux linkages and the permanent magnet rotor flux linkage

$\omega_{r}: \quad$ Electrical rotor speed, $(\mathrm{rad} / \mathrm{s})$

$\omega_{b}: \quad$ Base speed, $(\mathrm{rad} / \mathrm{s})$. 


\section{Conflict of Interests}

The authors declare that there is no conflict of interests regarding the publication of this paper.

\section{References}

[1] P. Vas, Sensorless Vector and Direct Torque Control, Oxford University Press, 1998.

[2] S. K. Sul, Control of Electric Machine Drive Systems, IEEE Press, 2011.

[3] I. Boldea and S. A. Nasar, Electric Drives, CRC Press, 2006.

[4] J. W. Finch and D. Giaouris, "Controlled AC electrical drives," IEEE Transactions on Industrial Electronics, vol. 55, no. 2, pp. 481-491, 2008.

[5] M.-S. Nicolae and I.-R. Bojoi, "A control strategy for an induction motor used for vehicular traction and/or positioning systems with variable speeds," in Proceedings of the International Conference on Applied \& Theoretical Electricity (ICATE '12), pp. 1-6, IEEE, Craiova, Romania, October 2012.

[6] B. K. Bose, Modern Power Electronics and AC Drives, Prentice Hall PTR, 2002.

[7] R. Krishnan, Electric Motor Drives: Modeling, Analysis, and Control, Prentice Hall, Upper Saddle River, NJ, USA, 2001.

[8] M. P. Kazmierkowski, R. Krishnan, and F. Blaabjerg, Control in Power Electronics: Selected Problems, Academic Press, 2002.

[9] P. Pillay and R. Krishnan, "Modeling of permanent magnet motor drives," IEEE Transactions on Industrial Electronics, vol. 35, no. 4, pp. 537-541, 1988.

[10] R. Krishnan, Permanent Magnet Synchronous and Brushless DC Motor Drives, CRC Press, 2010.

[11] H. A. Rub, A. Iqbal, and J. Guzinski, High Performance Control of AC Drives with MATLAB/SIMULINK, Wiley, 2012.

[12] S.-M. Sue, T.-W. Hung, J.-H. Liaw, Y.-F. Li, and C.-Y. Sun, "A new MTPA control strategy for sensorless V/f controlled PMSM drives," in Proceedings of the 6th IEEE Conference on Industrial Electronics and Applications (ICIEA '11), pp. 1840-1844, Beijing, China, June 2011.

[13] M. N. Razavi, H. Abniki, and M. K. Zadeh, "An optimal control strategy for the IPM motor drives," in Proceedings of the IEEE Electrical Power and Energy Conference (EPEC '09), pp. 1-6, IEEE, Montreal, Canada, October 2009.

[14] R. Bennett, C. S. Edrington, and F. Fleming, "Application of a maximum torque per ampere control strategy for DSRM drives," in Proceedings of the IEEE Vehicle Power and Propulsion Conference (VPPC '08), pp. 1-6, Harbin, China, September 2008.

[15] Z. Wenjuan, H. Shoudao, G. Jian, and L. Ting, "Curve analog control of maximum torque per ampere for permanent magnet synchronous motor used in electric vehicles," in Proceedings of the 3rd IEEE International Conference on Power Engineering, Energy \& Electrical Drives (PowerEng '11), pp. 1-5, IEEE, Málaga, Spain, May 2011.

[16] F. Tahami, H. Nademi, and M. Rezaei, "A high-performance vector-controlled PMSM drive with maximum torque per ampere operation," in Proceedings of the IEEE 2nd International Power and Energy Conference (PECon '08), pp. 254-258, Johor Bahru, Malaysia, December 2008.

[17] R. Na, X. Wang, Y. Cao, and L. Mao, "Adaptive input-output feedback linearization control for IP MSM using maximum Torque Per Ampere strategy," in Proceedings of the 6th International Forum on Strategic Technologies, vol. 2, pp. 684-689, August 2011.
[18] S. Huang, Z. Chen, K. Huang, and J. Gao, "Maximum torque per ampere and flux-weakening control for PMSM based on curve fitting," in Proceedings of the IEEE Vehicle Power and Propulsion Conference (VPPC '10), pp. 1-5, Lille, France, September 2010.

[19] W. Wang, B. Fahimi, and M. Kiani, "Maximum torque per ampere control of permanent magnet synchronous machines," in Proceedings of the 20th International Conference on Electrical Machines (ICEM '12), pp. 1013-1020, IEEE, Marseille, France, September 2012.

[20] Z. Li and H. Li, "MTPA control of PMSM system considering saturation and cross-coupling," in Proceedings of the 15th International Conference on Electrical Machines and Systems, pp. 1-5, Sapporo, Japan, October 2012.

[21] K.-W. Lee and S. B. Lee, "MTPA operating point tracking control scheme for vector controlled PMSM drives," in Proceedings of the International Symposium on Power Electronics, Electrical Drives, Automation and Motion ( SPEEDAM '10), pp. 24-28, IEEE, Pisa, Italy, June 2010.

[22] M. C. Paicu, L. Tutelea, I. Boldea, G. D. Andreescu, and R. Ancuti, "PM-RSM sensorless vector control: zero q-axis flux versus approximate maximum torque per current, with experiments," in Proceedings of the 12th International Conference on Optimization of Electrical and Electronic Equipment (OPTIM '10), pp. 460-468, IEEE, Braşov, Romania, May 2010.

[23] D. Xu, T. Wang, J. Liu, and H. Wei, "Research on optimal-torque control method of permanent magnet synchronous motor," in Proceedings of the 3rd IEEE Conference on Industrial Electronics and Applications (ICIEA '08), pp. 1229-1233, Singapore, June 2008.

[24] C. B. Butt, M. A. Hoque, and M. A. Rahman, "Simplified fuzzy logic based MTPA speed control of IPMSM drive," IEEE Transactions on Industry Applications, vol. 40, no. 6, pp. 15291535, 2004.

[25] R. Monajemy, Control strategies and parameter compensation for permanent magnet synchronous motor drives [Ph.D. dissertation], Virginia Tech, Blacksburg, Va, USA, 2000.

[26] E. Al-Nabi, B. Wu, N. R. Zargari, and V. Sood, "Input power factor compensation for high-power CSC fed PMSM drive using d-axis stator current control," IEEE Transactions on Industrial Electronics, vol. 59, no. 2, pp. 752-761, 2012.

[27] F. Wu, S.-M. Wan, and S.-H. Huang, "Unity power factor control for PMSM position sensorless drive," in Proceedings of the 11th International Conference on Electrical Machines and Systems (ICEMS '08), pp. 1618-1620, Wuhan, China, October 2008.

[28] M. F. Moussa, A. Helal, Y. Gaber, and H. A. Youssef, "Unity power factor control of permanent magnet motor drive system," in Proceedings of the 12th International Middle East Power System Conference (MEPCON '08), pp. 360-367, Aswan, Egypt, March 2008.

[29] P. D. Chandana Perera, Sensorless control of permanent-magnet synchronous motor drives [Ph.D. dissertation], Aalborg University, Aalborg, Denmark, 2002.

[30] R. Monajemy and R. Krishnan, "Control and dynamics of constant power loss based operation of permanent magnet synchronous motor drive system," in Proceedings of the 25th IEEE Annual Conference of the Industrial Electronics Society, vol. 3, pp. 1452-1457, IEEE, December 1999.

[31] Z. Xiaotan, L. Chongjian, L. Yaohua, and W. Chengsheng, "Analysis of a large power PMSM using different control methods," in Proceedings of the 8th International Conference on Electrical Machines and Systems (ICEMS '05), vol. 1, pp. 416-421, IEEE, Nanjing, China, September 2005. 
[32] A. El Shahat and H. El Shewy, "PM synchronous motor control strategies with their neural network regression functions," Journal of Electrical Systems, vol. 5, no. 4, pp. 1-16, 2009.

[33] J. Li, J. J. Yu, and Z. Chen, "A review of control strategies for permanent magnet synchronous motor used in electric vehicles," Applied Mechanics and Materials, vol. 321-324, pp. 1679-1685, 2013. 

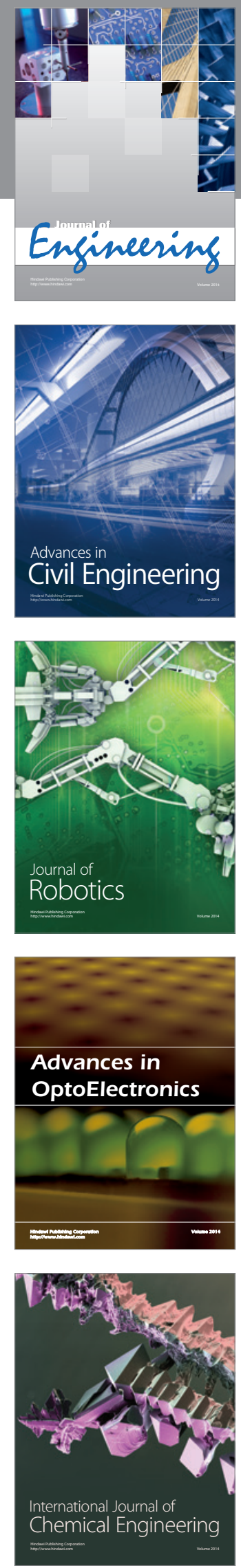

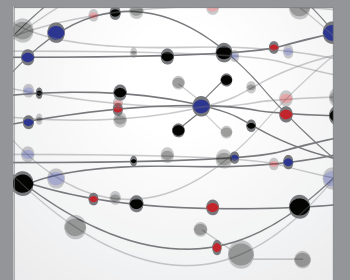

The Scientific World Journal
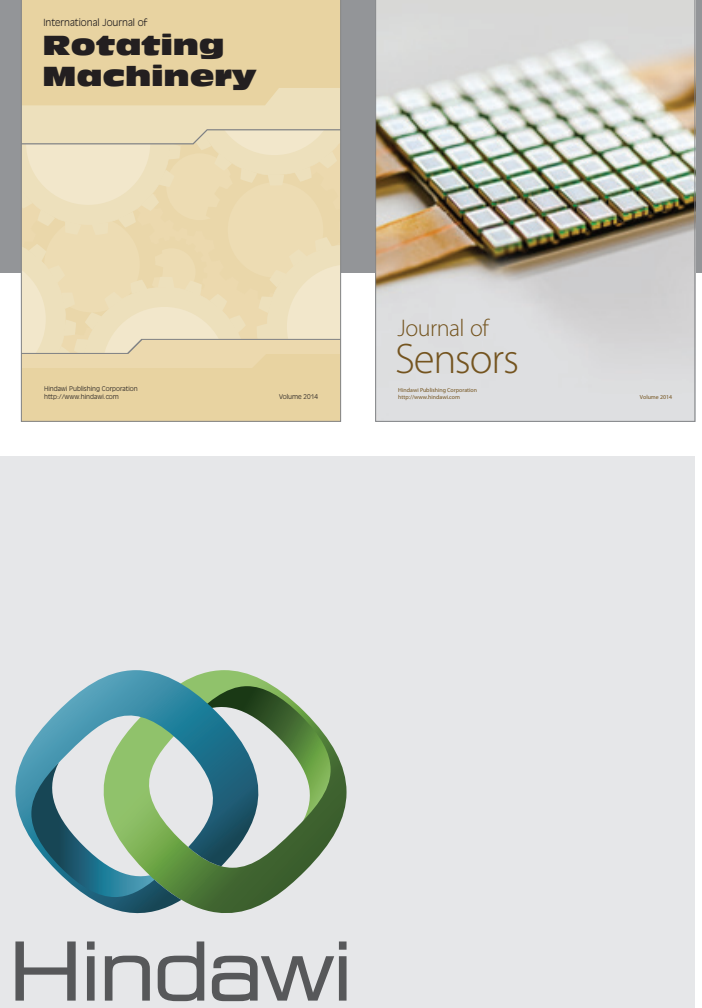

Submit your manuscripts at http://www.hindawi.com
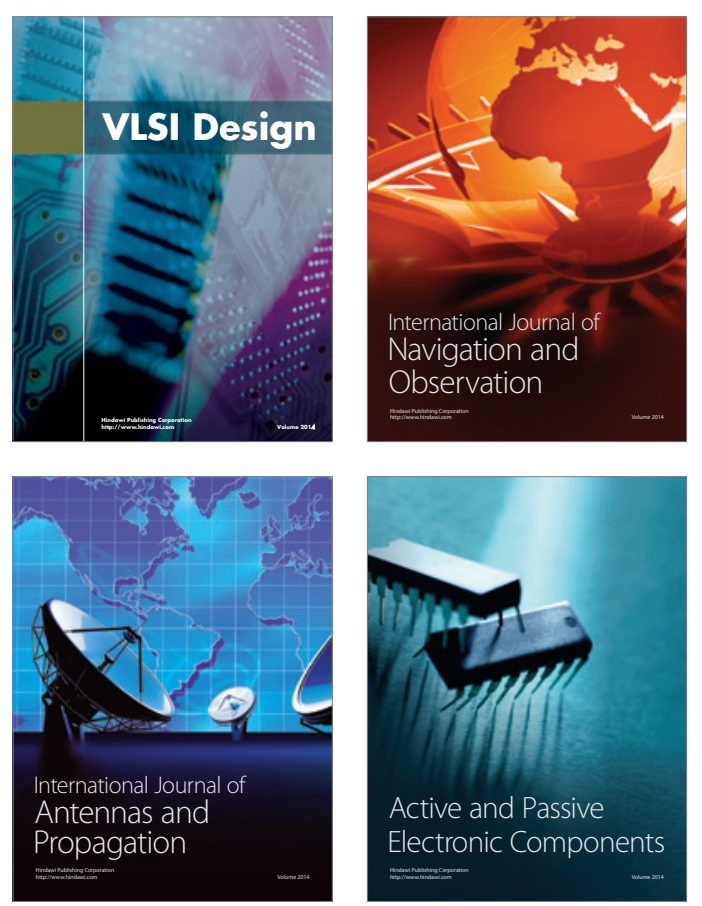
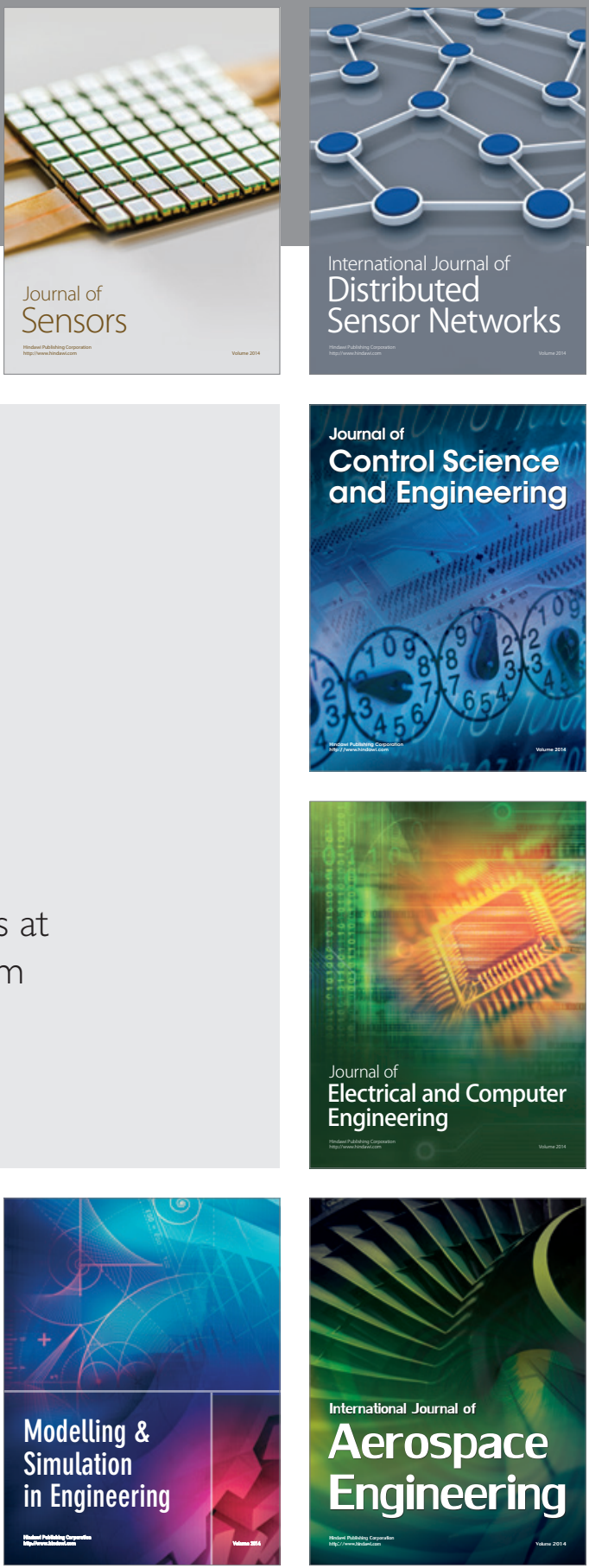

Journal of

Control Science

and Engineering
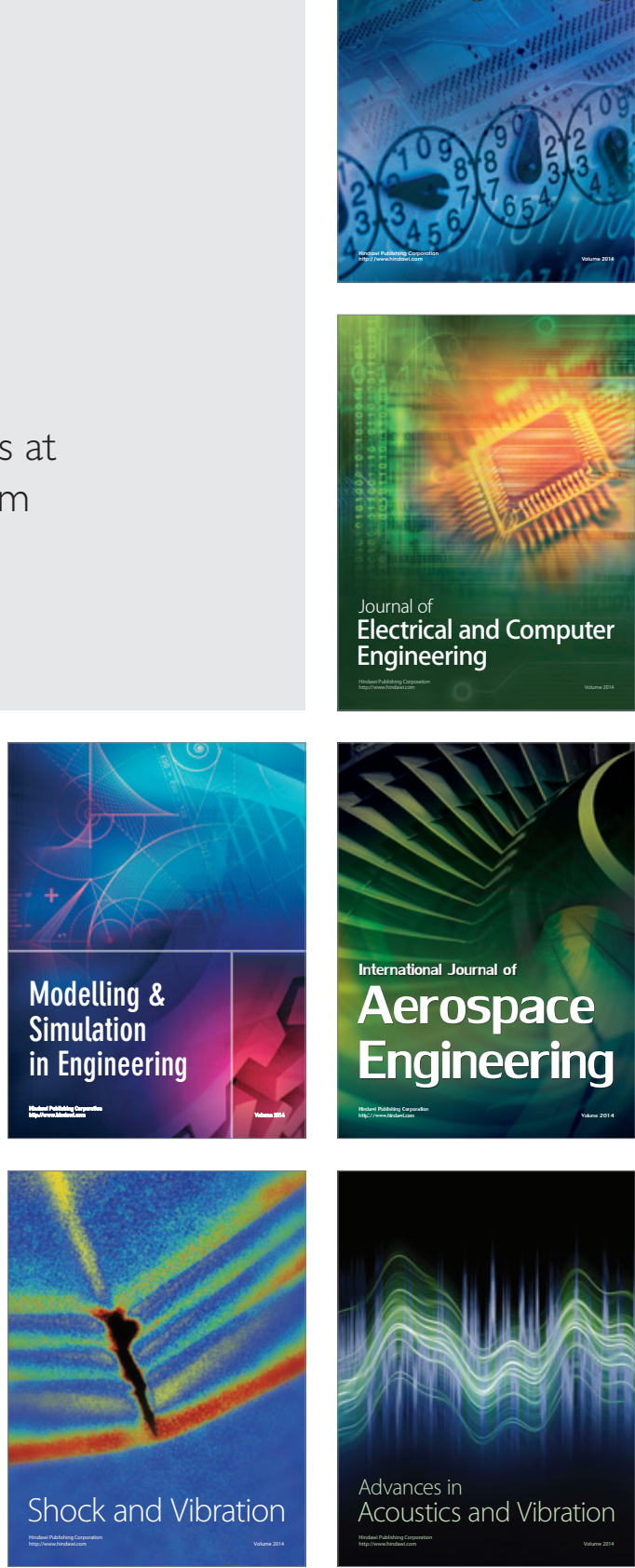